\title{
Icariin improves testicular dysfunction via enhancing proliferation and inhibiting mitochondria-dependent apoptosis pathway in high-fat diet and streptozotocin-induced diabetic rats
}

Weiguo He ${ }^{1 \dagger}$, Huiqing Liu ${ }^{1 \dagger}$, Linlin $\mathrm{Hu}^{2 \dagger}$, Yaohui Wang ${ }^{3}$, Lane Huang ${ }^{1}$, Aihong Liang ${ }^{1}$, Xuan Wang ${ }^{1}$, Qing Zhang ${ }^{3}$, Yi Chen ${ }^{3}$, Yi CaO $^{3}$, Suyun Li ${ }^{1^{*}}$, Junli Wang ${ }^{2^{*}}$ and Xiaocan Lei ${ }^{i^{*}}$

\begin{abstract}
Background: Diabetes mellitus (DM), a chronic metabolic disease, severely impairs male reproductive function. However, the underpinning mechanisms are still incompletely defined, and there are no effective strategies or medicines for these reproductive lesions. Icariin (ICA), the main active component extracted from Herba epimedii, is a flavonoid traditionally used to treat testicular dysfunction. Whether ICA can improve male reproductive dysfunction caused by DM and its underlying mechanisms are still unclear. In this study, by employing metformin as a comparative group, we evaluated the protective effects of ICA on male reproductive damages caused by DM and explored the possible mechanisms.

Methods: Rats were fed with a high fat diet (HFD) and then intraperitoneally injected with streptozotocin (STZ) to induce diabetes. Diabetic rats were randomly divided into T2DM + saline group, T2DM + metformin group and T2DM + ICA group. Rats without the treatment of HFD and STZ were used as control group. The morphology of testicular tissues was examined by histological staining. The mRNA expression levels were determined by quantitative real-time PCR. Immunostaining detected the protein levels of proliferating cell nuclear antigen (PCNA), hypoxiainducible factor 1-alpha (HIF-1a) and sirtuin 1 (SIRT1) in testicular tissues. TUNEL assay was performed to determine cell apoptosis in the testicular tissues. The protein expression levels of HIF-1a and SIRT1 in the testicular tissues were determined by western blot assay.
\end{abstract}

Results: ICA effectively improved male reproductive dysfunction of diabetic rats. ICA administration significantly decreased fasting blood glucose (FBG) and insulin resistance index (IRI). In addition, ICA increased testis weight,

\footnotetext{
*Correspondence: lisuyun1163@163.com; baisewangjunli@163.com; 2019000013@usc.edu.cn

tWeiguo He, Huiqing Liu and Linlin Hu contributed equally to this work.

${ }^{1}$ Clinical Anatomy and Reproductive Medicine Application Institute,

Hengyang Medical School, University of South China, Hengyang 421001,

China

${ }^{2}$ Reproductive Medicine Center, The Affiliated Hospital of Youjiang

Medical University for Nationalities, Baise 533000, China

Full list of author information is available at the end of the article
}

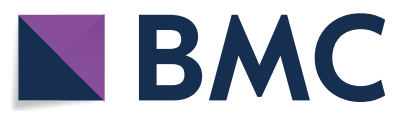

(c) The Author(s) 2021. Open Access This article is licensed under a Creative Commons Attribution 4.0 International License, which permits use, sharing, adaptation, distribution and reproduction in any medium or format, as long as you give appropriate credit to the original author(s) and the source, provide a link to the Creative Commons licence, and indicate if changes were made. The images or other third party material in this article are included in the article's Creative Commons licence, unless indicated otherwise in a credit line to the material. If material is not included in the article's Creative Commons licence and your intended use is not permitted by statutory regulation or exceeds the permitted use, you will need to obtain permission directly from the copyright holder. To view a copy of this licence, visit http://creativecommons.org/licenses/by/4.0/. The Creative Commons Public Domain Dedication waiver (http://creativeco mmons.org/publicdomain/zero/1.0/) applies to the data made available in this article, unless otherwise stated in a credit line to the data. 
epididymis weight, sperm number, sperm motility and the cross-sectional area of seminiferous tubule. ICA recovered the number of spermatogonia, primary spermatocytes and Sertoli cells. Furthermore, ICA upregulated the expression of PCNA, activated SRIT1-HIF-1 a signaling pathway, and inhibited intrinsic mitochondria dependent apoptosis pathway by upregulating the expression of $\mathrm{BCl}-2$ and downregulating the expression of Bax and caspase 3 .

Conclusion: These results suggest that ICA could attenuate male reproductive dysfunction of diabetic rats possibly via increasing cell proliferation and decreasing cell apoptosis of testis. ICA potentially represents a novel therapeutic strategy against DM-induced testicular damages.

Keywords: Icariin, Reproductive protection, Spermatogenesis, Proliferation, Apoptosis

\section{Introduction}

Diabetes mellitus (DM), characterized with hyperglycemia, is a chronic metabolic disease resulting from dysfunction in insulin secretion and/or insulin action [1, 2]. Recently, the morbidity of DM rapidly increased [3]. Owning to the complex and severe complications [3], DM has become one of the major causes of death [4], severely threatening the health and social economy of the world [5]. There is a close link between the morbidity of DM and the infertility [6]. Increasing striplings at reproductive age, even in children, have been diagnosed with DM [7]. Furthermore, growing evidence shows that hyperglycemia in DM can broadly impair male reproduction system [8-13], accompanying with severely histological damage of testis including the morphological disruption of seminiferous tubular and the disturbance of spermatogenesis $[7,11,14]$, decrease in serum sexual hormone, increase in oxidative stress and apoptosis in testis [7]. However, the underlying mechanisms of male reproductive impairments caused by DM are still incompletely defined, and there are no effective strategies or medicines for these reproductive lesions [7].

Currently, screening effective drug candidates from traditional Chinese medicine has attracted increasing attention [15]. Studies have found that various compounds from herbal extracts such as alpha-lipoic acid, resveratrol and cinnamon showed protective effects on the male reproduction systems under diabetic conditions [16-18]. Icariin (ICA), the main active component of Herba epimedii, is a flavonoid traditionally be used to treat erectile dysfunction $[19,20]$. Several studies indicated that ICA administration with moderate dose could promote spermatogenesis by elevating the levels of follicular stimulating hormone receptor (FSHR) and increasing testosterone secretion via upregulating the expression of steroidogenic acute regulatory protein (StAR) and peripheral type benzodiazepine receptor (PBR), which is indispensable element of the steroidogenic machinery and functions in a coordinated manner to transfer cholesterol into mitochondria [19, 21, 22]. Moreover, Nan et al. found that ICA could stimulate the proliferation of Sertoli cells [23], which play an important role in regulating the self-renewal and differentiation of spermatogonial stem cells $[24,25]$. Correspondingly, ICA also ameliorated microcystin-LR-induced and aging-related Sertoli cell injury $[26,27]$, then increased the epididymal sperm count [19]. These results suggest that ICA could benefit male reproductive function by regulating the hypothalamic-pituitary-gonadal (HPG) axis [28]. Some recent studies also indicated the anti-apoptotic properties of ICA in other systems [15]. In cardiomyocytes, it is reported that ICA reduced oxidative stress and ameliorated apoptosis through alleviating mitochondrial dysfunction [29-32]. Qiao et al. showed that ICA pretreatment attenuated cisplatin-induced nephrotoxicity via reducing the levels of reactive oxygen species (ROS) and suppressing mitochondria dependent apoptotic pathway [33]. Wang et al., found that ICA enhanced neuronal viability and attenuated neuronal death [34], and Zhu et al., further confirmed this conjecture [35]. Sun et al., also verified the attenuated effect of ICA on high glucose-induced cell apoptosis and oxidative stress in human umbilical venous endothelial cells [36]. Furthermore, Zhao et al., confirmed that ICA could inhibit AGE-induced PC12 cell injury by specifically targeting $\mathrm{Bax}$, then further regulate mitochondrial apoptosis process [37]. These studies suggested that the anti-apoptosis effect of ICA is tightly linked to classical mitochondria apoptosis pathway [15]. Consequently, it is rational to speculate that mitochondria apoptosis pathway may involve the protective effects of ICA on male reproductive system. Indeed, the normal development of germ cells and reproductive tissues is highly dependent on balanced regulation of mitochondrial apoptosis by BCL-2 family proteins [38], and there is a correlation between increased testis damage and higher mitochondrial apoptosis in diabetic rats [14, 39]. However, the effect of ICA on male reproductive dysfunction of diabetic rats and the underlying mechanisms are still not defined.

In this study, comparing with metformin, we evaluated the protective roles of ICA on the DM-induced testicular dysfunction via establishing a high fat diet (HFD) and streptozotocin (STZ) induced diabetic rat model. We sought to identify the effect of ICA on cell proliferation 
and apoptosis in the testis of diabetic rats. We speculated that ICA could effectively attenuate DM-induced male reproductive damages and may provide a potentially therapeutic strategy against male infertility caused by DM.

\section{Materials and methods \\ Animals and reagents}

Male Sprague-Dawley rats (6 weeks old, body weight $170 \pm 10 \mathrm{~g}$ ), purchased from the Animal Experimental Center of Daping hospital, Third Military Medical University, were maintained in an air-conditioned animal facility with a $12 \mathrm{~h}$ light/dark cycle. Rats were provided with standard food pellets and tap water ad libitum, and this study was approved by the Animal Ethics Committee of University of South China (NO.. USC2020031602). Streptozotocin (STZ) was purchased from Sigma-Aldrich (S0130, St. Louis, USA), Metformin and ICA were purchased from Sigma-Aldrich (St. Louis, USA) and Xi'an Xiaocaokeji Ltd. (Xi'an, China) respectively. Rats were fed with a high fat diet (HFD, consisting of 70\% standard food pellet, $10 \%$ fat and $20 \%$ sugar) and then intraperitoneally injected with STZ $(45 \mathrm{mg} / \mathrm{kg})$ to induce diabetes. Fasting blood glucose (FBG) levels, which were tested for 3 days after the injection of STZ, over $16.7 \mathrm{mM}$ were considered as type 2 diabetic rats (T2DM) [14]. Then, T2DM were randomly divided into three groups including $\mathrm{T} 2 \mathrm{DM}+$ saline group, $\mathrm{T} 2 \mathrm{DM}+$ metformin group and T2DM + ICA group ( $n=6$ for each group). In addition, extra 6 rats without the treatment of HFD and STZ were employed as control group [14]. After scanning the optimal dose, $100 \mathrm{mg} / \mathrm{kg} / \mathrm{d}$ of metformin (dissolved in saline solution) and $80 \mathrm{mg} / \mathrm{kg} / \mathrm{d}$ of ICA (dissolved in $1 \%$ sodium carboxymethyl cellulose) were orally administered to T2DM for 6 weeks in T2DM + Metformin and T2DM + ICA group, respectively [40]. At the end of treatment period, all rats were anesthetized with $30 \mathrm{mg} /$ $\mathrm{kg}$ of pentobarbital sodium before sacrifice.

\section{Assessment of diabetic rats}

After fasting overnight, FBG and fasting blood insulin levels (FINS) were tested with a Glucose Meter (Contournext, Parsippany, USA) and an insulin kit (Abcan, Cambridge, USA), respectively. HOMA-IR was calculated with the following formula: $(\mathrm{FBG} \times \mathrm{FINS}) / 22.5$ [14].

\section{Hormonal analysis}

The serum levels of testosterone, luteinizing hormones (LH) and follicle-stimulating hormone (FSH) in the rats were analyzed using the commercial kits from Elabscience ${ }^{\circledR}$ Biotechnology Inc. (Houston, USA) according to the manufacturer's instruction [41].

\section{Sperm analysis}

For the sperm collection, cauda epididymis of all rat testis was collected and then transferred to a sterilized Petri dish with $2 \mathrm{~mL}$ normal saline. Sperm counting and motility analysis were performed according to the standard procedure [14] by a masterly operator with a Sperm Class Analyzer (MICROPTIC, Barcelona, Spain).

\section{Histological analysis}

For histology, partial testis tissue was fixed in $4 \%$ paraformaldehyde overnight. Paraffin sections $(6 \mu \mathrm{m})$ were sequentially cut, deparaffined and further stained with hematoxylin and eosin. The microstructure of testes, counting of spermatogonia, primary spermatocytes and Sertoli cell were photographed and performed under a light microscope (OLYMPUS BX43). For the counting, 10 randomly chosen seminiferous tubules in each slide (3 slides per rat) and totally 180 seminiferous tubules were selected, and the cross-sectional area of seminiferous tubules employed were analyzed by OPLYMPUS cell Sens Standard (Version 1.15).

\section{Immunohistochemical analysis}

Immunohistochemistry was performed according to previous study with minor modification [14]. Partial testes were fixed in $4 \%$ formaldehyde and embedded in paraffin. Then, sections $(6 \mu \mathrm{m})$ were sequentially permeabilized with $1 \%$ Triton X-100 in phosphate buffered saline (PBS) for $30 \mathrm{~min}$ at room temperature, boiled in $100 \mathrm{mM}$ sodium citrate $(\mathrm{pH} 6.0)$ three times $(6 \mathrm{~min}$ each) with $5 \mathrm{~min}$ intervals for antigen retrieval, washed in $3 \%$ hydrogen peroxide for $30 \mathrm{~min}$ to remove endogenous peroxidase and blocked for $1 \mathrm{~h}$ in $5 \%$ bovine serum albumin at room temperature. After that, slides were first incubated overnight at $4{ }^{\circ} \mathrm{C}$ with primary antibodies of proliferating cell nuclear antigen (PCNA; 1:100 dilution, sc-25,280, Santa Cruz Biotechnology, CA, USA), sirtuin 1 (SIRT1; 1:100 dilution, ab189494, Abcam, Cambridge, UK) and hypoxia-inducible factor 1-alpha (HIF-1 $\alpha$; 1:100 dilution, ab228649, Abcam, Cambridge, UK) in the blocking solution respectively, then further rewarmed for $45 \mathrm{~min}$ at $37^{\circ} \mathrm{C}$ the next day. Following three washes with $0.1 \%$ Tween-20 in PBS, the samples were incubated with rabbit anti-goat BiotinSP-conjugated antibody (1:100 dilution, SA00004-4, Protein Tech Group Inc., Wuhan, China) in the blocking solution for $45 \mathrm{~min}$ at room temperature and $45 \mathrm{~min}$ at $37^{\circ} \mathrm{C}$, respectively. The immunoreactive signals were detected with Peroxidase-conjugated Streptavidin (1:100 dilution, SA00001-0, Protein Tech Group, Wuhan, China). The normal goat IgG (1:200 dilution) 
was used as a negative control. Finally, sections were observed and photographed with an Olympus DP70 digital camera mounted on a Leica DMR microscope.

\section{TUNEL assay}

For apoptotic analysis, TUNEL assay was carried out by following the manufacturer's instructions (Roche Diagnostic Systems, Branchburg, NJ, USA) with minor modification [14]. Briefly, sections were deparaffined and rehydrated, and then sequentially treated with proteinase $\mathrm{K}$ and 3\% hydrogen peroxide, following the incubation with the TUNEL reaction mixture in a humid chamber at $37^{\circ} \mathrm{C}$. Then, 3, 3-diaminobenzidine chromogen were applied for the detection of peroxidase-conjugated antibiotin antibody. Finally, slices were counterstained with Hematoxylin. Sections without TdT-enzyme treatment were used as a negative control. Quantitative analysis of apoptotic cells was performed according to previous study [14] with minor modification. Only spermatogonia, primary spermatocytes and Sertoli cells were taken into account owning to the difficulty of quantification.

\section{Quantitative real-time PCR (qRT-PCR) assay}

Total RNA was extracted from the testes of rats with TRIzol reagent (Themo Fisher, Inc., USA). cDNA was synthesized with the TransScript II One-Step gDNA Removal and cDNA Synthesis SuperMix kit (Transgen Biotech, Beijing, China) according to the manufacturer's protocol. By using GAPDH as the internal reference, quantitative
PCR analyses were carried out in the SYBR Green assay system with the Applied Biosystems 7500 Real-time PCR System (Applied Biosystems, Foster City, CA, USA). The mRNA expression levels were calculated by using the $2^{-\Delta \Delta \mathrm{Ct}}$ method. The primers used in this study were listed in Table 1.

\section{Western blotting assay}

The testes of rats were lysed in RIPA buffer with $0.1 \%$ cocktail and $10 \%$ phosphotransferase inhibitor. Total protein from each sample was subjected to sodium dodecyl sulphate-polyacrylamide gel electrophoresis and subsequently transferred to nitrocellulose membranes (BIO-RAD, Hercules, CA, USA, $0.22 \mu \mathrm{M}$ ). Transferred membranes were blocked with $5 \%$ non-fat milk containing TBST (TBS containing $0.1 \%$ Tween-20) for $45 \mathrm{~min}$ at room temperature. Thereafter, primary antibodies including SIRT1 (1:1000 dilution, ab189494, Abcam, Cambridge, UK), HIF-1 $\alpha$ (1:1000 dilution, ab228649, Abcam, Cambridge, UK) and $\beta$-actin (1:1000 dilution, ab8227, Abcam, Cambridge, UK) were respectively incubated overnight at $4{ }^{\circ} \mathrm{C}$ and three washing were performed before the incubation of horseradish peroxidaseconjugated goat anti-rabbit IgG (secondary antibody, 1:1500 dilution, sc-2004; Santa Cruz Biotechnology, CA, USA) for $30 \mathrm{~min}$ at room temperature. Finally, Bio-Rad ChemiDoc system was used to analyze the intensities of autoradiographic bands.

Table 1 Primer pairs and corresponding annealing temperatures used in this study

\begin{tabular}{|c|c|c|c|}
\hline Gene & Sequence $\left(5^{\prime}-3^{\prime}\right)$ & Annealing Temperature & Product (bp) \\
\hline PCNA & $\begin{array}{l}\text { F: GCTCCATCCTGAAGAAGGT } \\
\text { R:TGCACTAAGGAGACGTGAGA }\end{array}$ & $55^{\circ} \mathrm{C}$ & 121 \\
\hline \multirow[t]{2}{*}{ Bax } & F:GAGACACCTGAGCTGACCTT & $55^{\circ} \mathrm{C}$ & 104 \\
\hline & R:TCCATGTTGTTGTCCAGTTC & & \\
\hline \multirow[t]{2}{*}{$\mathrm{BCl}-2$} & F:AGTACCTGAACCGGCATCT & $55^{\circ} \mathrm{C}$ & 120 \\
\hline & R:TCTTCAGAGACAGCCAGGA & & \\
\hline \multirow[t]{2}{*}{ Caspase-3 } & F:CCGGTTACTATTCCTGGAGA & $55^{\circ} \mathrm{C}$ & 117 \\
\hline & R:TAACACGAGTGAGGATGTGC & & \\
\hline SIRT1 & $\begin{array}{l}\text { F:GTGGCAGTAACAGTGACAGTG } \\
\text { R:GTCAGCTCCAGATCCTCCAG }\end{array}$ & $55^{\circ} \mathrm{C}$ & 143 \\
\hline HIF1a & $\begin{array}{l}\text { F:GATGGAATGGAGCAGAAGAC } \\
\text { R: CACAATCGTAACTGGTCAGC }\end{array}$ & $55^{\circ} \mathrm{C}$ & 112 \\
\hline CAT & $\begin{array}{l}\text { F: ACAACTCCCAGAAGCCTAAGAATG } \\
\text { R: RGCTTTTCCCTTGGCAGCTATG }\end{array}$ & $55^{\circ} \mathrm{C}$ & 76 \\
\hline Gpx & $\begin{array}{l}\text { F: GGAGAATGGCAAGAATGAAGA } \\
\text { R: RCCGCAGGAAGGTAAAGAG }\end{array}$ & $55^{\circ} \mathrm{C}$ & 139 \\
\hline SOD & $\begin{array}{l}\text { F: CGAGCATGGGTTCCATGTC } \\
\text { R: CTGGACCGCCATGTTTCTTAG }\end{array}$ & $55^{\circ} \mathrm{C}$ & 101 \\
\hline GAPDH & $\begin{array}{l}\text { F: CCTCAAGATTGTCAGCAATG } \\
\text { R: CAGTCTTCTGAGTGGCAGTG }\end{array}$ & $55^{\circ} \mathrm{C}$ & 134 \\
\hline
\end{tabular}




\section{Statistical analysis}

Statistical analyses were performed with SPSS 17.0 (IBM, Armonk, NY, USA). The normality of data was examined by Kolmogorov-Smirnov test. One-way ANOVA test followed by Dunnett's post hoc test were used to analyze the statistic differences among different groups. The data are presented as mean \pm standard deviation (SD), and $P<0.05$ was considered statistically significant.

\section{Results}

\section{ICA ameliorated diabetic parameters of diabetic rats}

According to the diagnostic criteria of DM $[1,2]$, we successfully established T2DM rat model. These diabetic rats showed significant decrease in body weight and increase in FBG, FINS and insulin resistance index (IRI) (Table 2). To test the efficiency of ICA, we examined the same parameters abovementioned in ICA-treated diabetic rats. ICA administration observably decreased FBG and IRI, but had no effect on body weight and FINS (Table 2). As a first-line drug for the management of hyperglycaemia [42-44], metformin was also employed as a comparative group to evaluate the efficiency of ICA. Similar to previous studies [14], metformin administration increased body weight and FINS, and decreased FBG and IRI (Table 2). The hormonal analysis results showed that the serum levels of testosterone, LH and FSH were significantly lower in the T2DM group than that in the control group (Fig. 1). Metformin and ICA administration both restored the sexual hormone levels when compared to T2DM group (Fig. 1).

\section{ICA mitigated testicular dysfunction of diabetic rats}

Previous studies have confirmed the causality between DM and male reproductive dysfunction [7]. To identify the protective role of ICA on male reproductive function, we first examined testis weight, epididymis weight, sperm number and sperm motility. Compared with T2DM group, there were obvious recovery in the four former parameters of both Metformin group and ICA group (Table 3), though the increase of the sperm number in
ICA group was not so comparable to that of Metformin group (Table 3). Then we further checked the histological structure of seminiferous epithelium. In T2DM group, the seminiferous tubules were severely atrophied to thin tube wall and the cross-sectional area of seminiferous tubule were significantly decreased (Fig. 2A and B). Within the inordinate seminiferous epithelium (Fig. 2A), the number of spermatogonia, primary spermatocytes and Sertoli cells were markedly reduced (Fig. 2C), and there were rare sperm in the lumen (Fig. 2A). In Metformin and ICA groups, however, the histological defects in male diabetic rats were obviously repaired (Fig. 2), especially the number of spermatogonia, primary spermatocytes and Sertoli cells (Fig. 2C).

\section{ICA upregulated the expression of proliferative PCNA}

Furthermore, we examined the distribution and expression of Proliferating cell nuclear antigen (PCNA), which plays a crucial role in the balance of cell survival and death $[45,46]$. Our results showed PCNA was detected in nearly all spermatogenic cells and Sertoli cells, and the strongest signal of PCNA staining was observed in the perimeter zone of seminiferous tubule where spermatogonia, primary spermatocytes and Sertoli cells mainly reside in (Fig. 3A). In T2DM group, the number of PCNA positive cells (Fig. 3B) and mRNA expression of Pcna (Fig. 3C) were significantly reduced and downregulated respectively. However, after the treatment of ICA, the PCNA signal and PCNA-positive cells were observably increased (Fig. 3A and B). Furthermore, the mRNA expression of Pcna were also markedly upregulated (Fig. 3C). Expectably, metformin administration showed similar effect when compared with that of ICA (Fig. 3). In addition, our qPCR results revealed that the mRNA expression levels of catalase (CAT), glutathione peroxidase (GPx) and superoxide dismutase (SOD) were significantly down-regulated in the testis of T2DM group when compared to control group (Fig. 4), and metformin and ICA treatment both partially restored the mRNA

Table 2 Effect of ICA on body weight, blood glucose, insulin levels and insulin resistance index in diabetic rats

\begin{tabular}{|c|c|c|c|c|c|c|}
\hline \multirow[t]{2}{*}{ Group } & \multicolumn{2}{|l|}{ BW (g) } & \multicolumn{2}{|l|}{$\mathrm{FBG}\left(\mathrm{mmol} \mathrm{L}^{-1}\right)$} & \multirow{2}{*}{$\begin{array}{l}\text { FINS } \\
\left(\text { ulU } \mathrm{mL}^{-1} \text { ) }\right.\end{array}$} & \multirow[t]{2}{*}{ IRI } \\
\hline & Before & After & Before & After & & \\
\hline Control & $341.2 \pm 7.644^{\diamond}$ & $402.5 \pm 8.705^{\mathrm{a} \diamond}$ & $6.150 \pm 0.5296^{a} \diamond$ & $4.817 \pm 0.1833^{a} \diamond$ & $73.89 \pm 15.00^{\mathrm{a}}$ & $20.96 \pm 0.940^{a}$ \\
\hline T2DM & $316.7 \pm 17.09 \diamond$ & $232.8 \pm 26.64^{b \triangleleft}$ & $22.07 \pm 0.7843^{b \diamond}$ & $27.48 \pm 0.9630^{\mathrm{b} \diamond}$ & $96.26 \pm 40.07^{b}$ & $188.5 \pm 51.80^{b}$ \\
\hline Metformin & $321.2 \pm 5.350^{\diamond}$ & $350.0 \pm 31.54^{\iota \diamond}$ & $18.10 \pm 0.5125^{b \triangleleft}$ & $5.000 \pm 0.4359^{a} \diamond$ & $188.9 \pm 82.10^{c}$ & $39.72 \pm 19.31^{c}$ \\
\hline ICA & $340.7 \pm 13.20^{\diamond}$ & $261.6 \pm 11.43^{b \diamond}$ & $22.43 \pm 0.7796^{\mathrm{b} \diamond}$ & $7.650 \pm 2.0840^{\mathrm{a} \diamond}$ & $118.2 \pm 13.62^{b}$ & $23.24 \pm 9.770^{a}$ \\
\hline
\end{tabular}

In each column, values assigned with different superscript lowercases (letters) indicate significant difference $(P<0.05)$. In each row of BW and FBG, values assigned with different superscript symbols (diamond symbols) also indicate significant difference $(P<0.05)$. BW body weight; $F B G$ fasting blood glucose; FINS fasting insulin; IRI insulin resistance index 

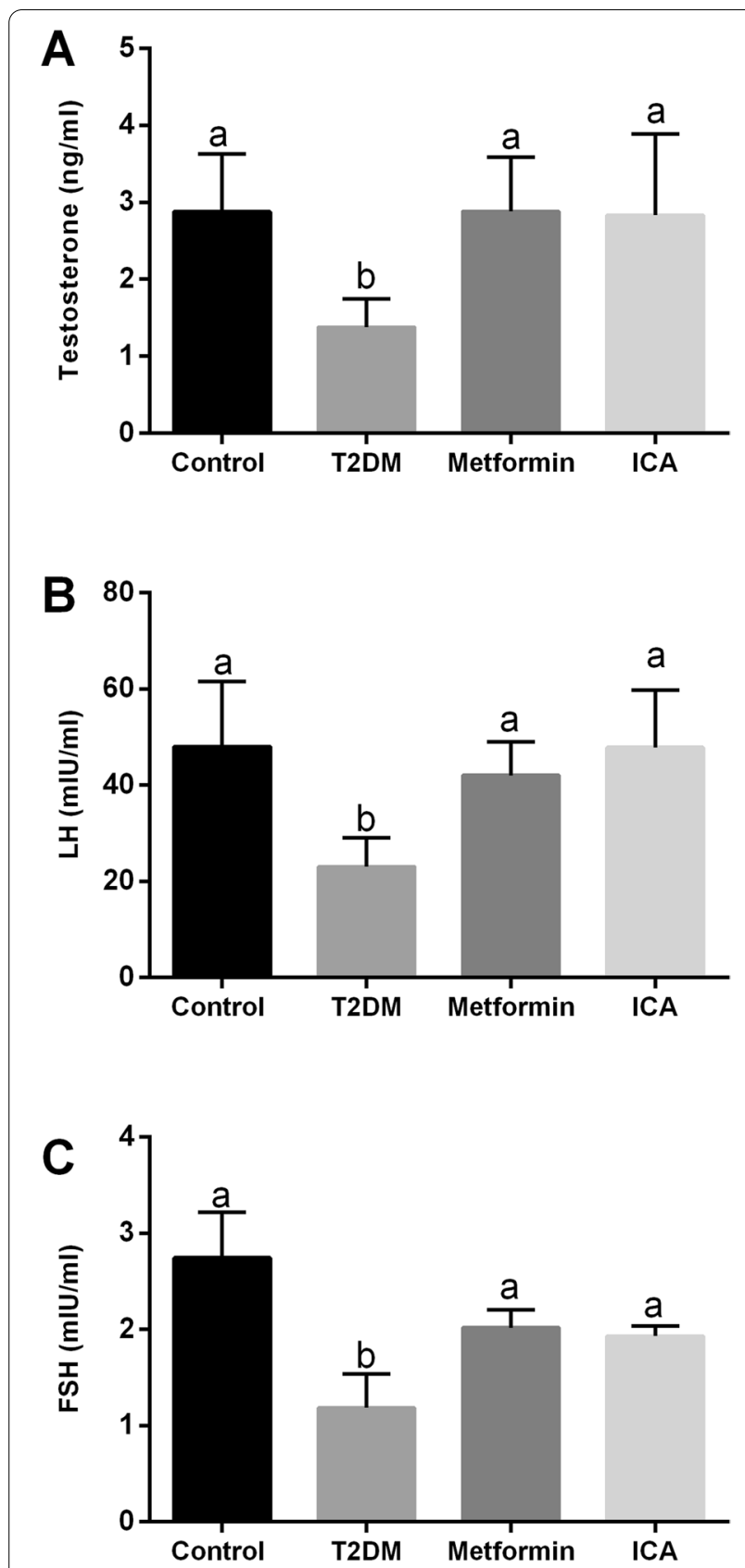

Fig. 1 Effects of ICA administration on the serum testosterone, LH and FSH levels in the diabetic rats. A Testosterone, (B) LH and (C) FSH levels are shown. $N=6$. Bars assigned with different superscripts mean significant difference $(p<0.05)$

expression levels of CAT, GPx and SOD in the testis of diabetic rats (Fig. 4).

\section{ICA activated SIRT1-HIF-1 $a$ axis}

Growing studies indicated that SIRT1, one of the most studied sirtuins, plays vital roles in spermatogenesis and male reproductive functions [47-51]. There is an apparent correlation between SIRT1 and insulin resistance [52]. In addition, SIRT1 could directly deacetylate and stabilize HIF-1 $\alpha$ [53, 54], a hypoxia activated transcription factor [55] that regulates the transcriptional response of hypoxia-responsive factors to protect spermatogenic cells against apoptosis in testis [56-58]. These results suggested an important protective roles of SIRT1HIF- $1 \alpha$ axis in repairing DM-induced male reproductive dysfunction [14]. Consequently, we further checked the activity of SIRT1-HIF-1 $\alpha$ axis. In T2DM group, the number of SIRT1 positive and HIF-1 $\alpha$ positive cells were both reduced (Fig. 5A and C). qRT-PCR and western blotting analysis showed an identical downregulation of Sirt1 and Hif- $1 \alpha$ (Fig. 5B, D and E). In contrast, ICA or metformin administration observably reversed these disorders, not only enhanced the signal of SIRT1 and HIF- $1 \alpha$ (Fig. 5A and $\mathrm{C}$ ) but also upregulated the expression of Sirt1 and Hif- $1 \alpha$ (Fig. 5B, D and E).

\section{ICA alleviated mitochondrial apoptosis signaling in diabetic rats}

Normal development of germ cells and reproductive system highly relies on balanced regulation of mitochondrial apoptosis by BCL-2 family proteins [38]. Several studies have proved the close relationship between the antiapoptotic effect of ICA and Bcl-2 signaling pathway [15, $35,59]$. Consequently, we also conducted TUNEL assay and identified the expression of mitochondria apoptosis pathway related genes, including $B c l-2, B a x$ and Caspase-3 (Fig. 6). Compared with the control group, the number of apoptosis cells in the seminiferous tubules of T2DM group were significantly increased, with apoptotic signal mainly focusing on the perimeter area (Fig. 6A and B). Furthermore, the mRNA expression of $\mathrm{Bcl}-2$ and $\mathrm{Bax}$ and Caspase- 3 showed significant downregulation and upregulation respectively (Fig. 6C). In contrast, in ICA and Metformin groups, the number of apoptotic cells were obviously decreased (Fig. 6A and B), and the mRNA expression of $\mathrm{Bcl}-2$ and $\mathrm{Bax}$ and Caspase-3 were significantly upregulated and downregulated respectively, especially in ICA group (Fig. 6C).

\section{Discussion}

ICA, DM and male reproductive dysfunction

Owning to complex complications, DM can severely impair reproduction [7, 9]. Hyperglycemia in DM can dramatically cause histological damages to the seminiferous tubular of testis $[11,12]$ including a reduction in the size of the seminiferous tubules and degeneration of spermatogonia and spermatocytes [60]. Hyperglycemia can also decrease sperm counts, sperm motility and semen volume $[61,62]$. In this study, HFD and STZ induced diabetic rats presented severely histological 
Table 3 Effect of ICA on testis weight, epididymis weight, sperm number and sperm motility

\begin{tabular}{lllll}
\hline Group & Testis Weight $(\mathbf{g})$ & Epididymis Weight $\mathbf{g})$ & Sperm number $\left(\times \mathbf{1 0}^{\mathbf{6}}\right)$ & Sperm motility $(\mathbf{\%})$ \\
\hline Control & $1.735 \pm 0.043^{\mathrm{a}}$ & $0.7274 \pm 0.048^{\mathrm{a}}$ & $154.7 \pm 21.85^{\mathrm{a}}$ & $13.46 \pm 3.29^{\mathrm{a}}$ \\
T2DM & $1.228 \pm 0.230^{\mathrm{b}}$ & $0.3805 \pm 0.0656^{\mathrm{b}}$ & $31.40 \pm 14.20^{\mathrm{b}}$ & $4.13 \pm 0.91^{\mathrm{b}}$ \\
Metformin & $1.657 \pm 0.079^{\mathrm{a}}$ & $0.5634 \pm 0.0464^{\mathrm{a}}$ & $230.7 \pm 72.6^{\mathrm{c}}$ & $13.10 \pm 1.89^{\mathrm{a}}$ \\
ICA & $1.516 \pm 0.143^{\mathrm{a}}$ & $0.4935 \pm 0.0328^{\mathrm{a}}$ & $132.6 \pm 71.65^{\mathrm{a}}$ & $12.27 \pm 5.380^{\mathrm{a}}$
\end{tabular}

In each column, values assigned with different superscripts indicate significant difference $(P<0.05)$

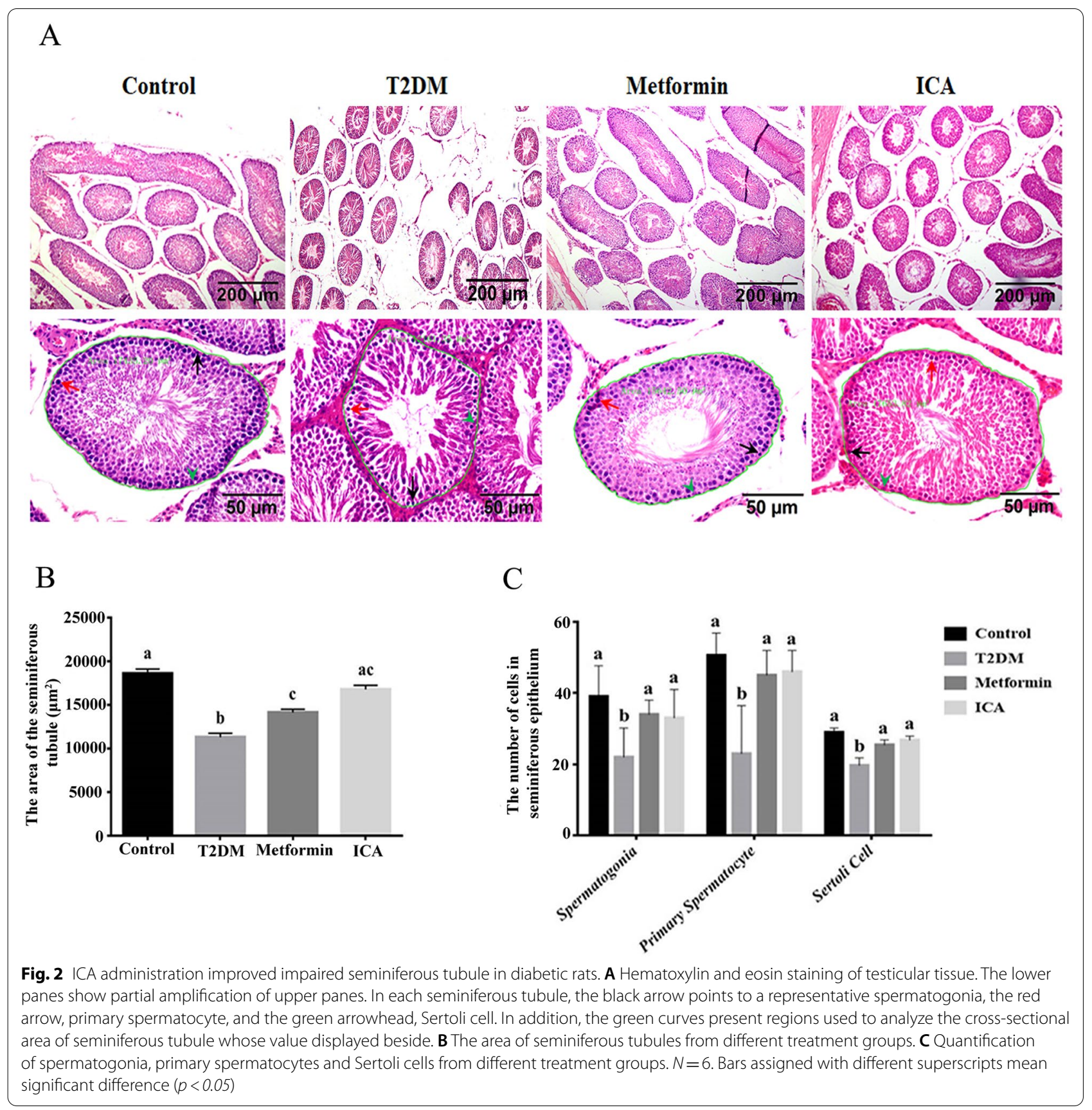




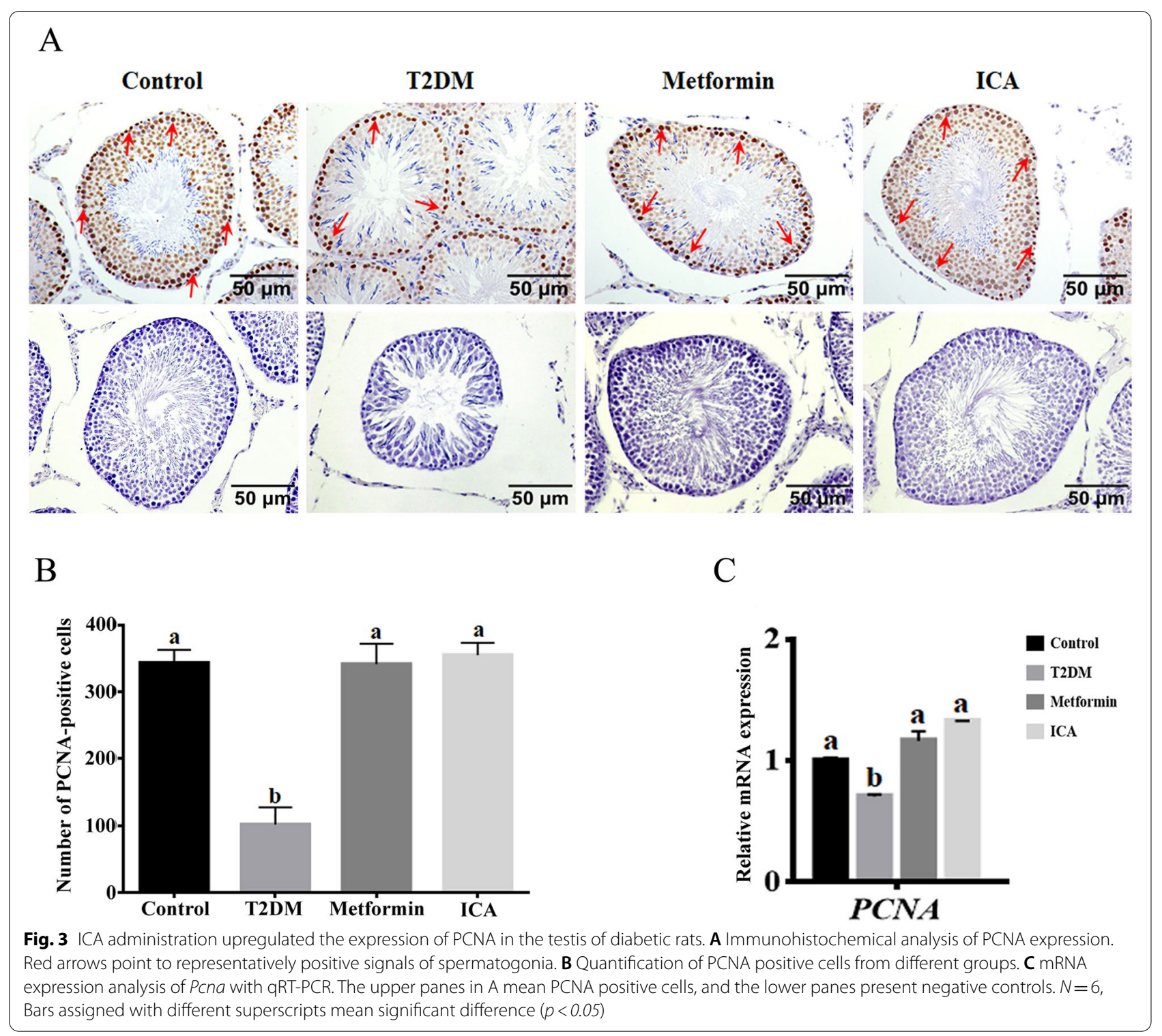

impairment, including reduced cross-sectional area and morphological disruption of seminiferous tubules and decreased number of spermatogonia, primary spermatocytes, Sertoli cells and sperm. In addition, significant increase in FBG and IRI, decrease in testis weight, epididymis weight, sperm number and sperm motility were also found. ICA administration effectively improved these male reproductive damages of diabetic rats.

\section{ICA and proliferation}

PCNA plays a vital role in the proliferation of spermatogonia, primary spermatocytes and Sertoli cells [63]. Indeed, HFD and STZ-induced diabetic rats showed dramatical downregulation of PCNA expression. This downregulation may lead to the dysfunction of combination of replication factors and proteins that involving in DNA replication, cell cycle control and repair, eventually causing the observable decline of spermatogonia, primary spermatocytes and Sertoli cells. ICA or metformin treatment not only recovered the expression of PCNA, but also increased the number of spermatogonia, primary spermatocytes and Sertoli cells.

SIRT1, mainly expressed in spermatocytes and spermatogonia, has been implicated in the germ cell development of males [50,51]. Sirt1 deficiency was found to attenuate spermatogenesis and germ cell function [64], delay the differentiation of spermatogenic stem cells [51], decrease sperm counts [64] and increase DNA 

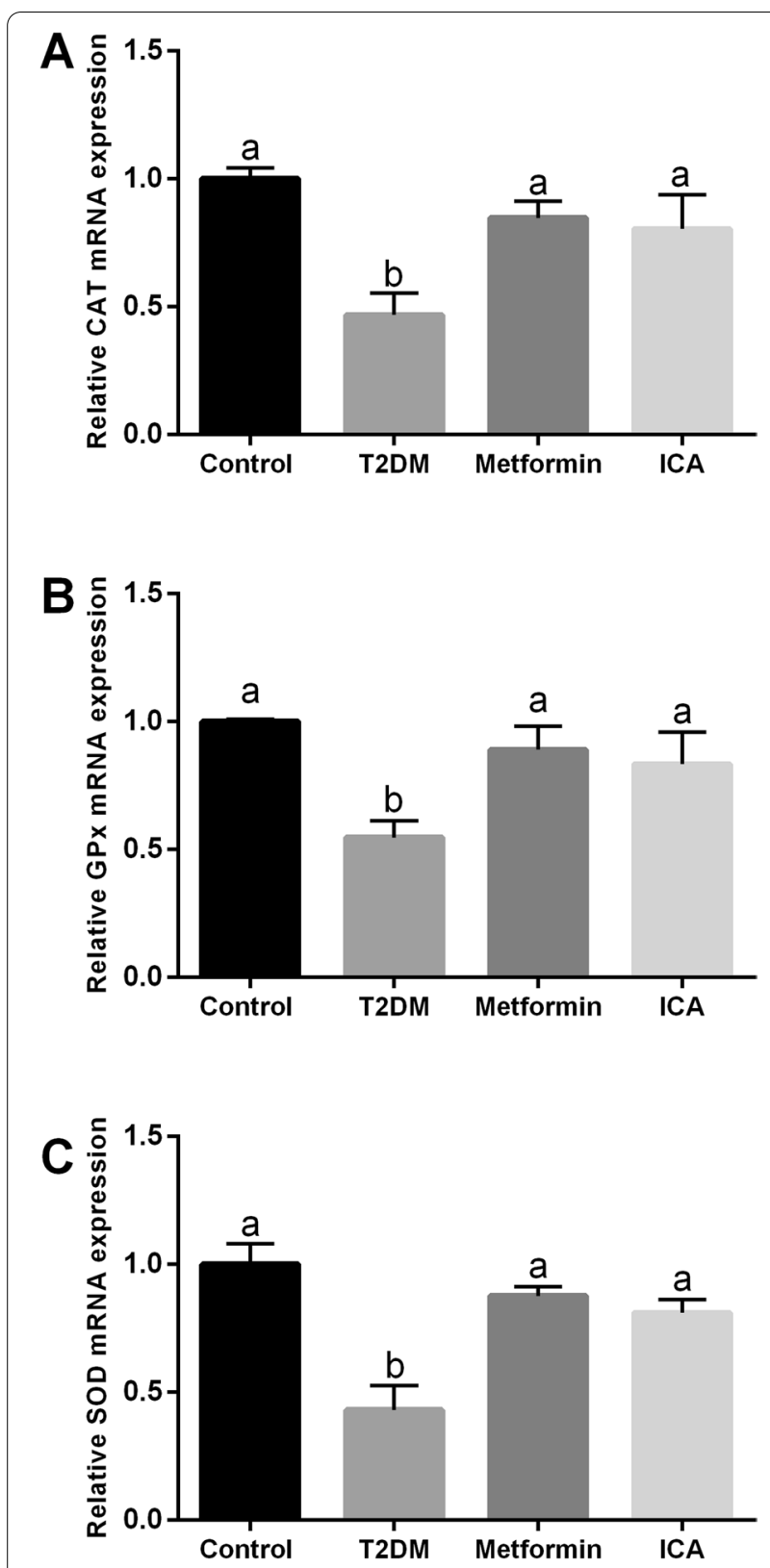

Fig. 4 Effects of ICA administration on the mRNA expression levels of CAT, GPx and SOD in the testis of diabetic rats. The mRNA expression levels of (A) CAT, (B) GPx and (C) SOD in the testis are shown. $N=6$. Bars assigned with different superscripts mean significant difference $(p<0.05)$

damages/lesions [51] and the apoptosis of pachytene spermatocytes [50]. Here, there were significant decrease in the expression of SIRT1 and reduction in the number of spermatogonia and primary spermatocytes in diabetic rats, which were consistent with previous study. After the treatment with ICA or metformin, the expression of SIRT1 and the number of spermatogonia and primary spermatocytes were observably upregulated and increased respectively, which indicated that ICA may improve DM-induced male reproductive dysfunctions potentially via upregulating the activity of SIRT1. Interestingly, though the treatment of metformin significantly increased FINS, ICA administration showed no significant difference to T2DM group. This may be due to the higher efficiency of ICA in protecting against IRI than metformin. In addition, Dodd et al., found the abnormal expression of HIF-1 $\alpha$, a direct target of SIRT1 $[53,54]$ in diabetic rats [65]. After the treatment with ICA or metformin, there was a significant upregulation of HIF-1 $\alpha$. Notably, this upregulation in ICA group showed an observable excess to that of Metformin group, indicating a possibly better efficiency of ICA in anti-hypoxia to that of metformin.

\section{ICA and apoptosis}

Apoptosis, a programmed cell death, is crucial for normal development and for maintaining the homeostasis of organism [38]. Proapoptotic protein Bax can activate mitochondria-dependent caspase signaling pathway to cause apoptosis. Anti-apoptotic protein $\mathrm{Bcl}-2$ prevents Bax from translocating to mitochondria to inhibit apoptosis [66-68]. The normal development of germ cells and reproductive system highly relies on the balanced regulation of mitochondrial apoptosis [38]. There were severe impairment of mitochondrion and endoplasmic reticulum in spermatogenic cells and Sertoli cells of diabetic rats [69]. However, there was no significant increase in the apoptosis of germ cell of the STZ-treated mice without hyperglycemia [70]. Interestingly, diabetic mice that were treated with insulin on 3d after STZ treatment displayed reduced elevation of whole-body glucose levels and inhibition of apoptotic cell death in the testis [71]. This suggests a close link between hyperglycemia and germ cell apoptosis in diabetes. Here, obvious apoptosis phenomenon was mainly found in perimeter region (near the basal membrane of seminiferous tubules) where mainly contains spermatogonia, primary spermatocytes and Sertoli cells. Importantly, these diabetic rats, with increased apoptosis in spermatogenic cells and Sertoli cells, presented severe hyperglycemia. In addition, TUNEL assay indicated that ICA or metformin administration significantly decreased the cell apoptosis in testis of diabetic rats. Both ICA and metformin treatments dramatically upregulated the expression of $\mathrm{Bcl}-2$ and downregulated the expression of Bax and Caspase-3 respectively, which is consistent with previous studies $[33,59]$. Notably, the expression of Bax and Caspase-3 in ICA group were obviously lower to that of Metformin group, which may be owning to that ICA not only upregulated the expression of Bcl-2 but also directly targeted 

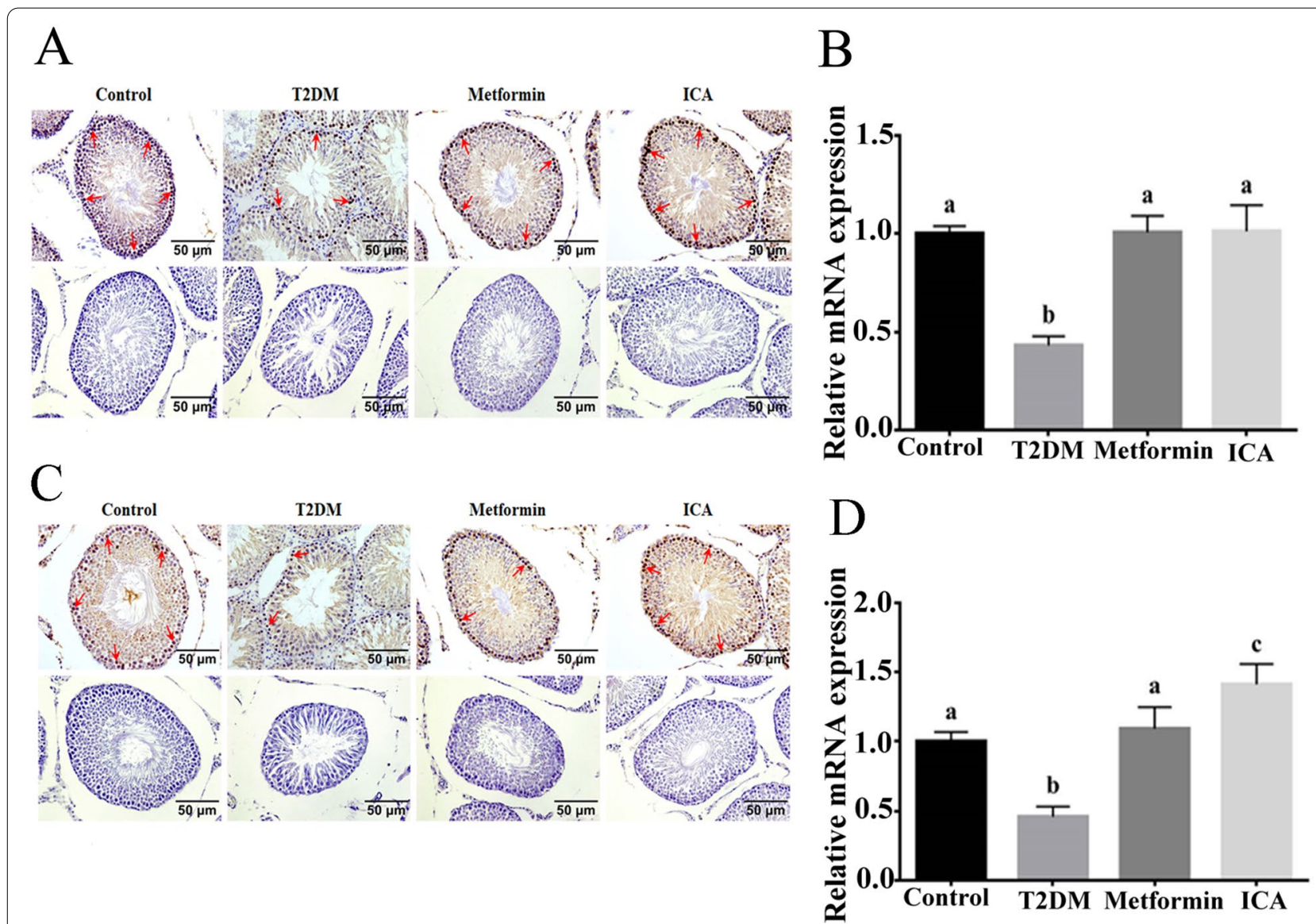

$\mathrm{E}$

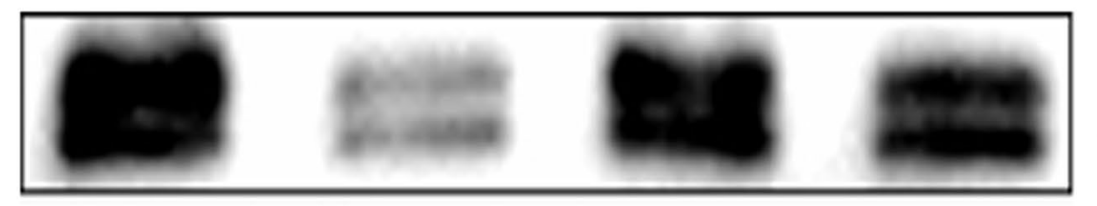

\section{SIRTl}

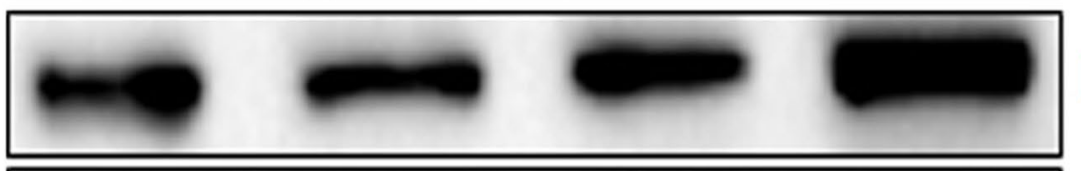

\section{HIF-l $\alpha$}

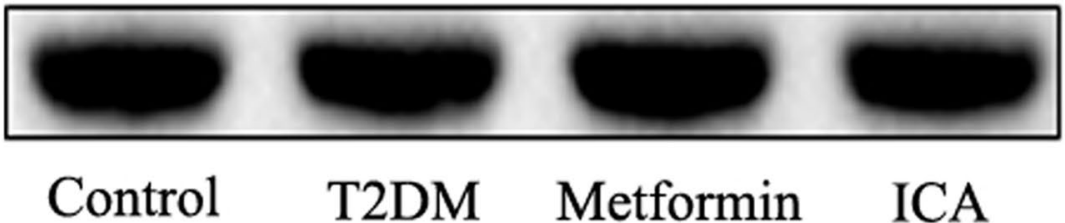

\section{$\beta$-actin}

Fig. 5 ICA administration upregulated the expression of SIRT1 and HIF-1a in the testis of diabetic rats. A Immunohistochemical analysis of SIRT1 expression, and red arrows show representatively positive signals of spermatogonia. B mRNA expression analysis of Sirt1 with qRT-PCR. D Immunohistochemical analysis of HIF-1 a expression. Red arrows show representatively positive signals of spermatogonia. D mRNA expression analysis of Hif-1 a with qRT-PCR. E Western blotting analysis of SIRT1 and HIF-1a protein expression. Bars assigned with different superscripts mean significant difference $(p<0.05)$ 


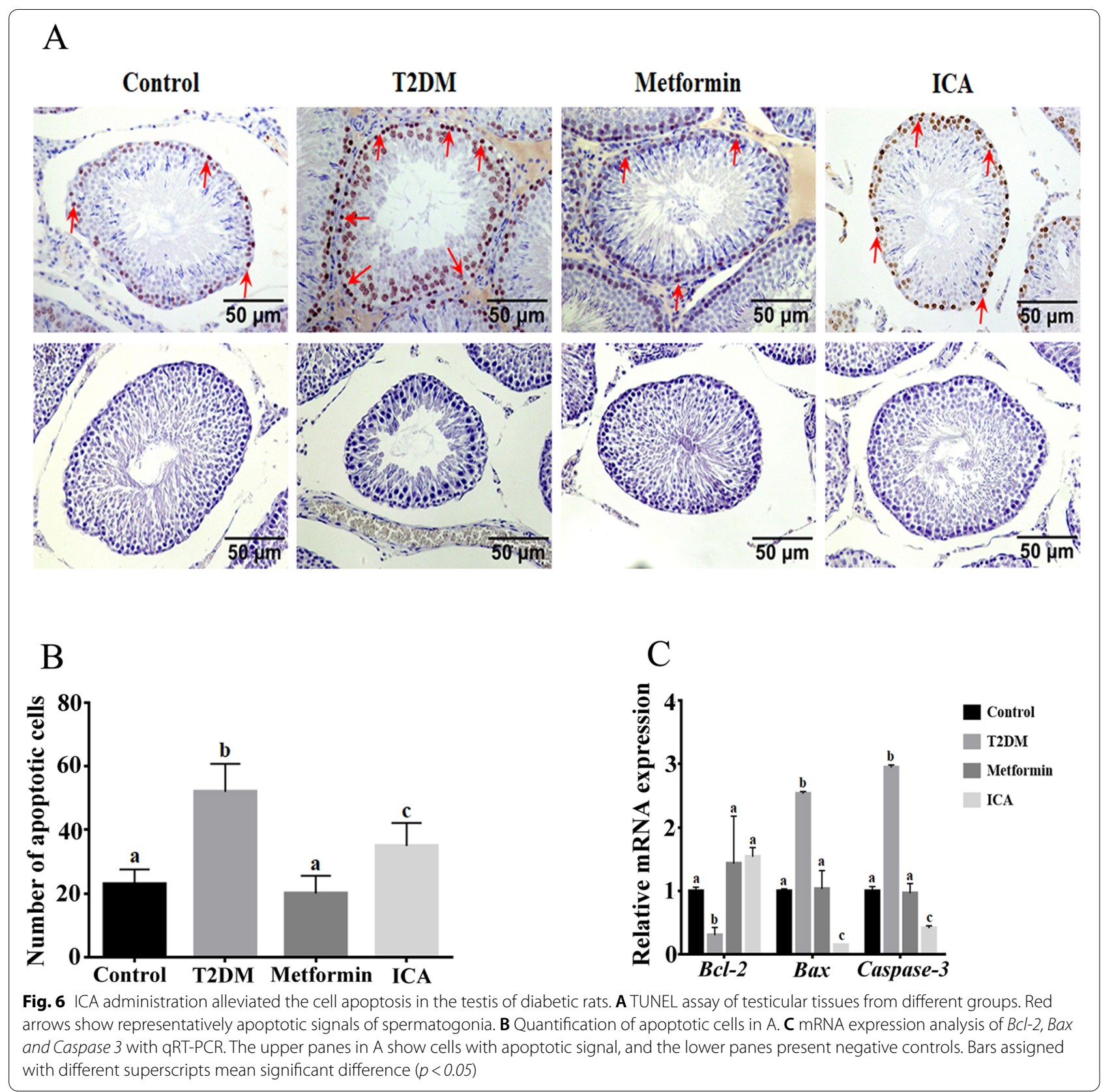

BAX and inhibited the translocation of Bax to mitochondria [59]. These results indicated that ICA showed better efficiency in attenuating the abnormal apoptosis of DM-induced male reproductive dysfunction. Nonetheless, comparing with Metformin group, though presented lower expression of Bax and Caspase-3 in the testis of diabetic rats, the ICA group showed apparently more apoptotic cells whose underlying mechanisms needs to be further investigated.

\section{Likely stimulation of ICA on the steroidogenesis and HPG} axis

It is well known that sexual hormone regulation is indispensable to maintain normal reproductive function [72]. Studies including clinical and animal models indicated a decreased serum levels of FSH, LH and testosterone in diabetes or diabetic animals $[10,13]$. However, ICA could present testosterone mimetic properties and upregulate the expression of testosterone and gonadal androgen receptor gene [21]. Chen et al., found that ICA not only increased the production of testosterone 
by regulating the expressions of StAR and PBR, but also improved spermatogenesis via regulating the expression of FSHR and claudin-11 [19]. Consequently, ICA could stimulate the secretion of male hormones and increase genital indexes through regulating the HPG axis [28]. In this study, our results showed that ICA upregulated the serum levels of testosterone, $\mathrm{LH}$ and FSH, which may facilitate the recovery of male reproductive functions in diabetic rats.

\section{Study limitations}

The present study lacks the gain- or loss-function studies by using activators or inhibitors of the above investigated signaling pathways, which further revealed the mechanistic actions of ICA. The study examined the mRNA expression levels of CAT, GPx and SOD in the testis, however, due to the limited samples, the levels of ROS production have not been examined our studies. The present study has not performed the detailed analysis in types of cells such as interstitial cells in the testis, which should be further explored in the future studies.

\section{Conclusion}

In conclusion, this study revealed that ICA can protect against DM-induced testicular dysfunction in rats possibly via enhancing cell proliferation and inhibiting intrinsic mitochondria-dependent apoptotic signaling respectively (Fig. 7). Our results demonstrate that ICA effectively attenuated DM-induced male reproductive dysfunctions and spermatogenesis deficiency. ICA may ameliorate DM-induced spermatogenesis deficiency possibly through increasing proliferation and inhibiting intrinsic mitochondria-dependent apoptotic pathway of spermatogonia, primary spermatocytes and Sertoli cells, respectively. Our findings suggested that ICA may be a potentially novel therapeutic agent for the protection and treatment of DM-induced testis damage.

\section{Acknowledgements}

None.

\section{Authors' contributions}

$\mathrm{WH}$ and $\mathrm{YW}$ conceived the research, analyzed the data and wrote the manuscript. HL, LH, AL, XW, QZ, YC and YC performed the research and writingreviewed the manuscript, JW and LH writing-reviewed the manuscript. SL and $\mathrm{XL}$ provided substantial contributions to conception and coordination. The author(s) read and approved the final manuscript.

\section{Funding}

This work was supported by the National Natural Science Fund of China (No. 81860733 and 82060293), Natural Science Foundation of Hunan Province(No. 2020JJ5500, 2018JJ3431), Outstanding youth fund of The Education Department of Hunan Province (Grant No. 2017SJQ13), the Science and Technology Fund of Guizhou Province (No. Qian Basic [2019]1344), Scientific Research Project of Hunan Education Department (18B584), Open fund of State Key Laboratory of Developmental Biology of Freshwater Fish (Grant No. 2017KF008), the Foundation of Central Government to Guide Local Scientific and Technological Development (No. ZY21195023), the Natural Science Foundation of Guangxi in China (No. 2018GXNSFAA050034 and 2019GXNSFBA245034),

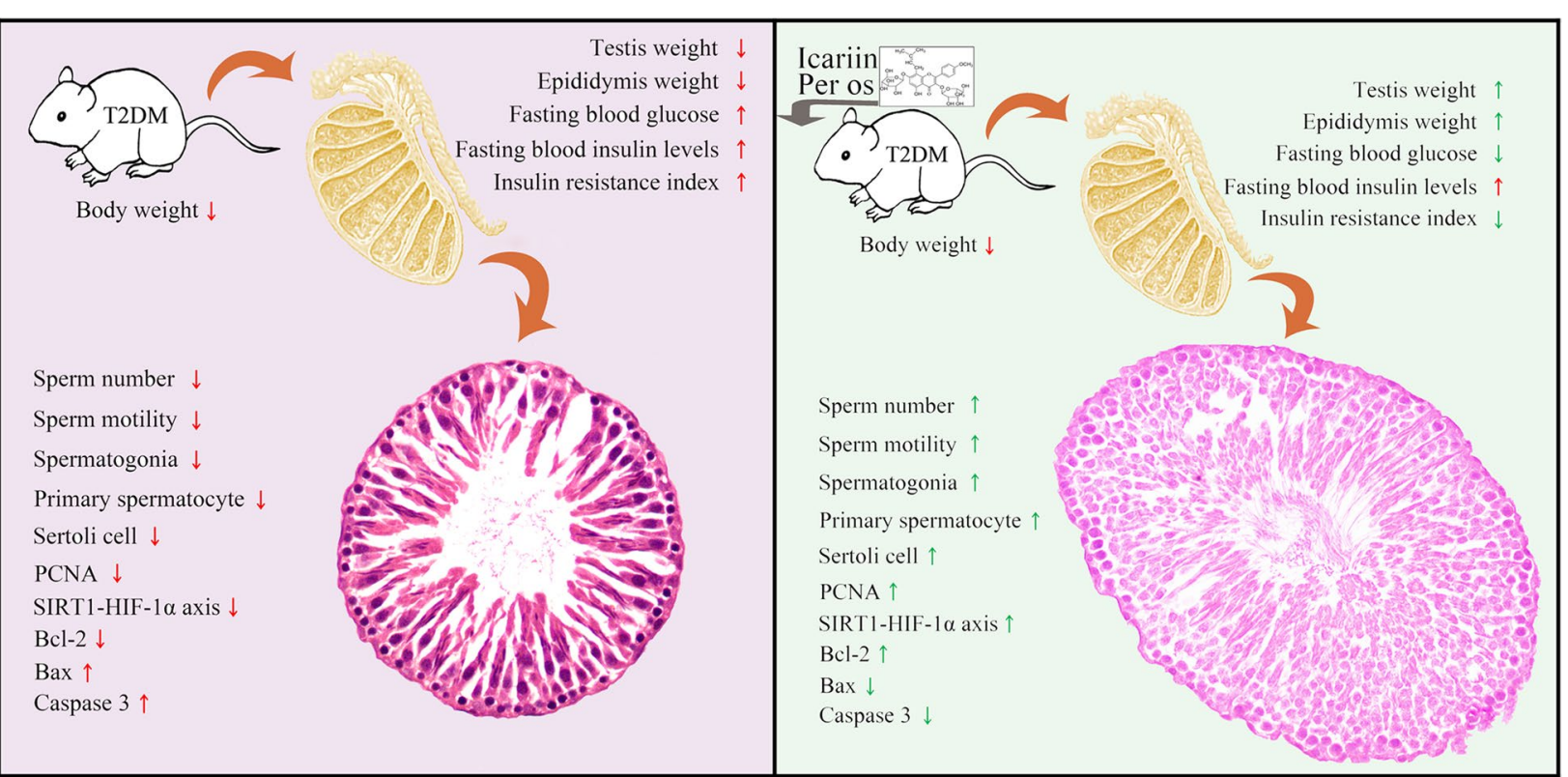

Fig. 7 Schematic illustrating ICA's protection against diabetes mellitus induced testicular dysfunction in rats possibly via enhancing cell proliferation and inhibiting intrinsic mitochondria dependent apoptotic signaling. Red arrows in T2DM panel mean deleterious effects (with significant difference) to reproductive function and relative parameters when compared with normal control group (nondiabetic). Red and green arrows in ICA treatment panel represent that there are no and obvious effectiveness respectively after ICA administration when compared with T2DM group 
National Innovation and Entrepreneurship Training Program for College Students (No. 201910661011 and ZYDC2018013).

\section{Availability of data and materials}

All the data were available upon the request from the corresponding authors.

\section{Declarations}

\section{Ethics approval and consent to participate}

All experiments were approved by the Animal Care Committee of University of South China (NO. USC2020031602) and followed the guidelines of the Administration of Affairs Concerning Animal Experimentation of China.

\section{Consent for publication}

Not applicable.

\section{Competing interests}

The authors have declared that no competing interest exists.

\section{Author details}

${ }^{1}$ Clinical Anatomy and Reproductive Medicine Application Institute, Hengyang Medical School, University of South China, Hengyang 421001, China. ${ }^{2}$ Reproductive Medicine Center, The Affiliated Hospital of Youjiang Medical University for Nationalities, Baise 533000, China. ${ }^{3}$ School of Basic Medical Sciences, Zunyi Medical University, Zunyi 563000, China.

Received: 1 March 2021 Accepted: 23 October 2021

Published online: 09 November 2021

\section{References}

1. American Diabetes A. Classification and diagnosis of Diabetes: standards of medical Care in Diabetes-2019. Diabetes Care. 2019;42:S13-28.

2. American Diabetes A. Diagnosis and classification of diabetes mellitus. Diabetes Care. 2014;37(Suppl 1):S81-90.

3. Zheng Y, Ley SH, Hu FB. Global aetiology and epidemiology of type 2 diabetes mellitus and its complications. Nat Rev Endocrinol. 2018;14:88-98.

4. Mortality GBD, Causes of death C. Global, regional, and national age-sex specific all-cause and cause-specific mortality for 240 causes of death, 1990-2013: a systematic analysis for the global burden of disease study 2013. Lancet. 2015;385:117-71.

5. Federation ID: IDF Diabetes atlas-9th edition. Diabetes Atlas http://www diabetesatlasorg/ 2019.

6. Bahmanzadeh M, Vahidinia A, Mehdinejadiani S, Shokri S, Alizadeh Z. Dietary supplementation with astaxanthin may ameliorate sperm parameters and DNA integrity in streptozotocin-induced diabetic rats. Clin Exp Reprod Med. 2016;43:90-6.

7. Shi GJ, Li ZM, Zheng J, Chen J, Han XX, Wu J, et al. Diabetes associated with male reproductive system damages: onset of presentation, pathophysiological mechanisms and drug intervention. Biomed Pharmacother. 2017;90:562-74.

8. Maresch CC, Stute DC, Alves MG, Oliveira PF, de Kretser DM, Linn T. Diabetes-induced hyperglycemia impairs male reproductive function: a systematic review. Hum Reprod Update. 2018;24:86-105.

9. Mulholland J, Mallidis C, Agbaje I, McClure N. Male diabetes mellitus and assisted reproduction treatment outcome. Reprod BioMed Online. 2011;22:215-9.

10. Tsounapi P, Honda M, Dimitriadis F, Kawamoto B, Hikita K, Muraoka K, et al. Impact of antioxidants on seminal vesicles function and fertilizing potential in diabetic rats. Asian J Androl. 2017;19:639-46.

11. Ghanbari E, Nejati V, Najafi G, Khazaei M, Babaei M. Study on the effect of royal jelly on reproductive parameters in streptozotocin-induced diabetic rats. Int J Fertil Steril. 2015;9:113-20.

12. Rashid K, Sil PC. Curcumin ameliorates testicular damage in diabetic rats by suppressing cellular stress-mediated mitochondria and endoplasmic reticulum-dependent apoptotic death. Biochim Biophys Acta. 1852;2015:70-82
13. Navarro-Casado L, Juncos-Tobarra MA, Chafer-Rudilla M, de Onzono LI, Blazquez-Cabrera JA, Miralles-Garcia JM. Effect of experimental diabetes and STZ on male fertility capacity. Study in rats. J Androl. 2010;31:584-92.

14. Lei $X$, Huo $P$, Wang $Y$, Xie $Y$, Shi Q, Tu H, et al. Lycium barbarum polysaccharides improve testicular Spermatogenic function in Streptozotocininduced diabetic rats. Front Endocrinol (Lausanne). 2020;11:164.

15. He C, Wang Z, Shi J. Pharmacological effects of icariin. Adv Pharmacol. 2020;87:179-203

16. Cui $X$, Jing $X$, Wu $X$, Yan $M$. Protective effect of resveratrol on spermatozoa function in male infertility induced by excess weight and obesity. Mol Med Rep. 2016;14:4659-65.

17. Khaki A, Khaki AA, Hajhosseini L, Golzar FS, Ainehchi N. The anti-oxidant effects of ginger and cinnamon on spermatogenesis dys-function of diabetes rats. Afr J Tradit Complement Altern Med. 2014;11:1-8.

18. Abbasi B, Molavi N, Tavalaee M, Abbasi H, Nasr-Esfahani MH. Alpha-lipoic acid improves sperm motility in infertile men after varicocelectomy: a triple-blind randomized controlled trial. Reprod BioMed Online. 2020;41:1084-91.

19. Chen M, Hao J, Yang Q, Li G. Effects of icariin on reproductive functions in male rats. Molecules. 2014;19:9502-14.

20. Low W-Y, Tan H-M. Asian traditional medicine for erectile dysfunction. J Mens Health Gender. 2007;4:245-50.

21. Zhang ZB, Yang QT. The testosterone mimetic properties of icariin. Asian J Androl. 2006:8:601-5.

22. Sun J, Wang D, Lin J, Liu Y, Xu L, Lv R, et al. Icariin protects mouse Leydig cell testosterone synthesis from the adverse effects of di(2-ethylhexyl) phthalate. Toxicol Appl Pharmacol. 2019;378:114612.

23. Nan $Y$, Zhang $X$, Yang G, Xie J, Lu Z, Wang W, et al. Icariin stimulates the proliferation of rat Sertoli cells in an ERK1/2-dependent manner in vitro. Andrologia. 2014;46:9-16.

24. Franca LR, Hess RA, Dufour JM, Hofmann MC, Griswold MD. The Sertoli cell: one hundred fifty years of beauty and plasticity. Andrology. 2016:4:189-212.

25. Vogl W, Lyon K, Adams A, Piva M, Nassour V. The endoplasmic reticulum, calcium signaling and junction turnover in Sertoli cells. Reproduction. 2018;155:R93-R104.

26. Zhou Y, Chen Y, Hu X, Guo J, Shi H, Yu G, et al. Icariin attenuate microcystin-LR-induced gap junction injury in Sertoli cells through suppression of Akt pathways. Environ Pollut. 2019;251:328-37.

27. Zhao H, You X, Chen Q, Yang S, Ma Q, He Y, et al. Icariin improves age-related testicular dysfunction by alleviating Sertoli cell injury via upregulation of the ERalpha/Nrf2-signaling pathway. Front Pharmacol. 2020;11:677.

28. Ding J, Tang Y, Tang Z, Zu X, Qi L, Zhang X, et al. Icariin improves the sexual function of male mice through the PI3K/AKT/eNOS/NO signalling pathway. Andrologia. 2018;50:e12802.

29. Wu B, Feng JY, Yu LM, Wang YC, Chen YQ, Wei Y, et al. Icariin protects cardiomyocytes against ischaemia/reperfusion injury by attenuating sirtuin 1-dependent mitochondrial oxidative damage. Br J Pharmacol. 2018;175:4137-53.

30. Song YH, Cai H, Zhao ZM, Chang WJ, Gu N, Cao SP, et al. Icariin attenuated oxidative stress induced-cardiac apoptosis by mitochondria protection and ERK activation. Biomed Pharmacother. 2016;83:1089-94.

31. Zhou H, Yuan Y, Liu Y, Deng W, Zong J, Bian ZY, et al. Icariin attenuates angiotensin II-induced hypertrophy and apoptosis in $\mathrm{H} 9 \mathrm{c} 2$ cardiomyocytes by inhibiting reactive oxygen species-dependent JNK and p38 pathways. Exp Ther Med. 2014;7:1116-22.

32. Ni T, Lin N, Huang X, Lu W, Sun Z, Zhang J, et al. Icariin ameliorates diabetic cardiomyopathy through Apelin/Sirt3 Signalling to improve mitochondrial dysfunction. Front Pharmacol. 2020;11:256.

33. Qiao C, Ye W, Li S, Wang H, Ding X. Icariin modulates mitochondrial function and apoptosis in high glucose-induced glomerular podocytes through $\mathrm{G}$ protein-coupled estrogen receptors. Mol Cell Endocrinol. 2018;473:146-55

34. Wang L, Zhang L, Chen ZB, Wu JY, Zhang X, Xu Y. Icariin enhances neuronal survival after oxygen and glucose deprivation by increasing SIRT1. Eur J Pharmacol. 2009;609:40-4

35. Zhu HR, Wang ZY, Zhu XL, Wu XX, Li EG, Xu Y. Icariin protects against brain injury by enhancing SIRT1-dependent PGC-1alpha expression in experimental stroke. Neuropharmacology. 2010;59:70-6. 
36. Sun S, Liu L, Tian X, Guo Y, Cao Y, Mei Y, et al. Icariin attenuates high glucose-induced apoptosis, oxidative stress, and inflammation in human umbilical venous endothelial cells. Planta Med. 2019;85:473-82.

37. Zhao SY, Liao LX, Tu PF, Li WW, Zeng KW. Icariin inhibits AGE-induced injury in $\mathrm{PC} 12$ cells by directly targeting apoptosis regulator Bax. Oxidative Med Cell Longev. 2019;2019:7940808.

38. Singh R, Letai A, Sarosiek K. Regulation of apoptosis in health and disease: the balancing act of BCL-2 family proteins. Nat Rev Mol Cell Biol. 2019:20:175-93.

39. Bayram S, Kizilay G, Topcu-Tarladacalisir Y. Evaluation of the Fas/FasL signaling pathway in diabetic rat testis. Biotech Histochem. 2016;91:204-11.

40. Xin H, Zhou F, Liu T, Li GY, Liu J, Gao ZZ, et al. Icariin ameliorates streptozotocin-induced diabetic retinopathy in vitro and in vivo. Int J Mol Sci. 2012;13:866-78

41. Behairy A, El-Sharkawy NI, Saber TM, Soliman MM, Metwally MMM, Abd El-Rahman Gl, et al. The modulatory role of vitamin C in Boldenone Undecylenate induced testicular oxidative damage and androgen receptor dysregulation in adult male rats. Antioxidants (Basel). 2020:9:1053.

42. Garber AJ, Abrahamson MJ, Barzilay Jl, Blonde L, Bloomgarden ZT, Bush MA, et al. Consensus statement by the American Association of Clinical Endocrinologists and American College of endocrinology on the comprehensive type 2 Diabetes management algorithm--2016 executive summary. Endocr Pract. 2016;22:84-113.

43. Inzucchi SE, Bergenstal RM, Buse JB, Diamant M, Ferrannini E, Nauck M, et al. Management of hyperglycaemia in type 2 diabetes, 2015: a patientcentred approach. Update to a position statement of the American diabetes association and the european association for the study of diabetes. Diabetologia. 2015;58:429-42.

44. Palmer SC, Mavridis D, Nicolucci A, Johnson DW, Tonelli M, Craig JC, et al. Comparison of clinical outcomes and adverse events associated with glucose-lowering drugs in patients with type 2 Diabetes: a Meta-analysis. JAMA. 2016;316:313-24.

45. Wang SC, Nakajima Y, Yu YL, Xia W, Chen CT, Yang CC, et al. Tyrosine phosphorylation controls PCNA function through protein stability. Nat Cell Biol. 2006;8:1359-68.

46. Azam N, Vairapandi M, Zhang W, Hoffman B, Liebermann DA. Interaction of CR6 (GADD45gamma ) with proliferating cell nuclear antigen impedes negative growth control. J Biol Chem. 2001:276:2766-74.

47. Seifert EL, Caron AZ, Morin K, Coulombe J, He XH, Jardine K, et al. SirT1 catalytic activity is required for male fertility and metabolic homeostasis in mice. FASEB J. 2012;26:555-66.

48. Caron AZ, He X, Mottawea W, Seifert EL, Jardine K, Dewar-Darch D, et al. The SIRT1 deacetylase protects mice against the symptoms of metabolic syndrome. FASEB J. 2014;28:1306-16.

49. McBurney MW, Yang X, Jardine K, Hixon M, Boekelheide K, Webb JR, et al. The mammalian SIR2alpha protein has a role in embryogenesis and gametogenesis. Mol Cell Biol. 2003;23:38-54.

50. Kolthur-Seetharam U, Teerds K, de Rooij DG, Wendling O, McBurney M, Sassone-Corsi P, et al. The histone deacetylase SIRT1 controls male fertility in mice through regulation of hypothalamic-pituitary gonadotropin signaling. Biol Reprod. 2009;80:384-91.

51. Bell EL, Nagamori I, Williams EO, Del Rosario AM, Bryson BD, Watson N, et al. SirT1 is required in the male germ cell for differentiation and fecundity in mice. Development. 2014;141:3495-504.

52. Liang F, Kume S, Koya D. SIRT1 and insulin resistance. Nat Rev Endocrinol. 2009:5:367-73.

53. Laemmle A, Lechleiter A, Roh V, Schwarz C, Portmann S, Furer C, et al. Inhibition of SIRT1 impairs the accumulation and transcriptional activity of HIF-1alpha protein under hypoxic conditions. PLoS One. 2012:7:e33433.

54. Joo HY, Yun M, Jeong J, Park ER, Shin HJ, Woo SR, et al. SIRT1 deacetylates and stabilizes hypoxia-inducible factor-1alpha (HIF-1alpha) via direct interactions during hypoxia. Biochem Biophys Res Commun. 2015:462:294-300.

55. Conde E, Alegre L, Blanco-Sanchez I, Saenz-Morales D, Aguado-Fraile E, Ponte $B$, et al. Hypoxia inducible factor 1-alpha (HIF-1 alpha) is induced during reperfusion after renal ischemia and is critical for proximal tubule cell survival. PLoS One. 2012;7:e33258.

56. Semenza GL, Wang GL. A nuclear factor induced by hypoxia via de novo protein synthesis binds to the human erythropoietin gene enhancer at a site required for transcriptional activation. Mol Cell Biol. 1992:12:5447-54.

57. Semenza GL. HIF-1: upstream and downstream of cancer metabolism. Curr Opin Genet Dev. 2010;20:51-6.

58. Chen Y, Zhang Y, Ji H, Ji Y, Yang J, Huang J, et al. Involvement of hypoxia-inducible factor-1alpha in the oxidative stress induced by advanced glycation end products in murine Leydig cells. Toxicol in Vitro. 2016:32:146-53.

59. Mo ZT, Li WN, Zhai YR, Gong QH. Icariin attenuates OGD/R-induced autophagy via BCl-2-dependent cross talk between apoptosis and autophagy in PC12 cells. Evid Based Complement Alternat Med. 2016;2016:4343084

60. Wang Y, Zhao H, Sheng X, Gambino PE, Costello B, Bojanowski K. Protective effect of Fructus Lycii polysaccharides against time and hyperthermia-induced damage in cultured seminiferous epithelium. J Ethnopharmacol. 2002;82:169-75.

61. Sm S, Mahaboob Basha P. Fluoride exposure aggravates the testicular damage and sperm quality in diabetic mice: protective role of ginseng and Banaba. Biol Trace Elem Res. 2017;177:331-44.

62. Adedara IA, Awogbindin IO, Anamelechi JP, Farombi EO. Garcinia kola seed ameliorates renal, hepatic, and testicular oxidative damage in streptozotocin-induced diabetic rats. Pharm Biol. 2015;53:695-704.

63. Tabara M, Shiraishi K, Takii R, Fujimoto M, Nakai A, Matsuyama H. Testicular localization of activating transcription factor 1 and its potential function during spermatogenesis. Biol Reprod. 2021;105:976-86.

64. Coussens M, Maresh JG, Yanagimachi R, Maeda G, Allsopp R. Sirt1 deficiency attenuates spermatogenesis and germ cell function. PLoS One. 2008:3:e1571.

65. Dodd MS, Sousa Fialho MDL, Montes Aparicio CN, Kerr M, Timm KN Griffin JL, et al. Fatty acids prevent hypoxia-inducible factor-1 alpha signaling through decreased succinate in Diabetes. JACC Basic Transl Sci. 2018:3:485-98

66. Agca CA, Tuzcu M, Gencoglu H, Akdemir F, Ali S, Sahin K, et al. Lycopene counteracts the hepatic response to 7,12-dimethylbenz[a]anthracene by altering the expression of $\mathrm{Bax}, \mathrm{BCl}-2$, caspases, and oxidative stress biomarkers. Pharm Biol. 2012;50:1513-8.

67. Liman N, Alan E, Bayram GK, Gurbulak K. Expression of survivin, BCl-2 and Bax proteins in the domestic cat (Felis catus) endometrium during the oestrus cycle. Reprod Domest Anim. 2013:48:33-45.

68. Lucinda LM, Aarestrup BJ, Peters VM, Reis JE, Oliveira RS, Guerra Mde O. The effect of the Ginkgo biloba extract in the expression of $\mathrm{Bax}, \mathrm{Bcl}-2$ and bone mineral content of Wistar rats with glucocorticoid-induced osteoporosis. Phytother Res. 2013;27:515-20.

69. Murray FT, Orth J, Gunsalus G, Weisz J, Li JB, Jefferson LS, et al. The pituitary-testicular axis in the streptozotocin diabetic male rat: evidence for gonadotroph, Sertoli cell and Leydig cell dysfunction. Int J Androl. 1981:4:265-80.

70. Vignera SL, Condorelli RA, Calogero AE. Relationship between diabetes mellitus type 1 and male reproductive function. Endocr Abstr. 2015:37:EP183.

71. Baccetti B, La Marca A, Piomboni P, Capitani S, Bruni E, Petraglia F, et al. Insulin-dependent diabetes in men is associated with hypothalamo-pituitary derangement and with impairment in semen quality. Hum Reprod. 2002;17:2673-7.

72. Ayuob NN, Murad HA, Ali SS. Impaired expression of sex hormone receptors in male reproductive organs of diabetic rat in response to oral antidiabetic drugs. Folia Histochem Cytobiol. 2015;53:35-48.

\section{Publisher's Note}

Springer Nature remains neutral with regard to jurisdictional claims in published maps and institutional affiliations. 